\title{
DOAÇÃO DE TECIDOS: DESFECHO DAS NOTIFICAÇÕES E CARACTERIZAÇÃO DOS DOADORES EM UM SERVIÇO DE PROCURA DE ÓRGÃOS E TECIDOS
}

\author{
Tissue donation: outcome of notifications and donors characterization \\ in an organs and tissues procurement service
}

\author{
Layse Beneli Prado', Clayton Gonçalves de Almeida ${ }^{2}$, Kátia Lacerda de Souza ${ }^{1}$, Amanda Silva de Macedo Bezerra', \\ Geórgia Pereira Silveira Souza', Jaquelini Pereira dos Santos ${ }^{1}$, Juliana Massonato Silva ${ }^{1}$, \\ César Augusto Guimarães Marcelino¹, Antônio Flávio Sanchez Almeida ${ }^{1}$, Andrea Cotait Ayoub ${ }^{1}$
}

\begin{abstract}
RESUMO
O número de transplantes de tecidos vem crescendo significativamente nos últimos dez anos. É considerado doador efetivo de tecidos o doador potencial com o diagnóstico de morte encefálica ou coração parado, do qual a família autorizou a doação de ao menos um tecido. Objetivo: Analisar o desfecho das notificações de possíveis doadores recebidas por um Serviço de Procura de Órgãos e Tecidos nos anos de 2011 e 2012, com relação à doação de tecidos e caracterizar os doadores efetivos de tecidos viabilizados nesse período. Método: Estudo documental, retrospectivo, descritivo-exploratório de abordagem quantitativa, realizado em um Serviço de Procura de Órgãos e Tecidos da cidade de São Paulo, através da análise das notificações de possíveis doadores recebidas nos anos de 2011 e 2012 e prontuários de doadores efetivos de tecidos viabilizados nesse período. Resultados: Das 785 notificações recebidas, 471 (60\%) culminaram em entrevista familiar, e destas, $256(54,3 \%)$ obtiveram consentimento familiar para doação, sendo que $225(87,9 \%)$ consentiram a doação de ao menos um tecido. Houve predominância de doadores do sexo masculino $(58,2 \%)$, referidos católicos $(39,6 \%)$, com média de idade de 44,7 anos, e causas-óbito de origem não traumática (60\%). Os tecidos mais doados foram: valvas cardíacas (96\%), seguido pelas córneas (84\%), vasos (55,6\%), ósteo-tendinoso $(45,3 \%)$ e pele $(43,6 \%)$. Conclusão: Não foi possível estabelecer relação de significância entre as variáveis de caracterização e todos os tecidos doados. Números aquém do esperado para a doação de tecidos fazem necessárias estratégias educativas voltadas à população e capacitação dos profissionais, visando elevar a disponibilidade de tecidos para transplante, contribuindo para o aumento da sobrevida de milhares de pessoas.
\end{abstract}

Descritores: Doadores de Tecidos; Morte Encefálica; Transplante de Tecidos; Obtenção de Tecidos e Órgãos; Enfermagem.

\footnotetext{
Instituição:

${ }^{1}$ Serviço de Procura de Órgãos e Tecidos do Instituto Dante Pazzanese de Cardiologia - São Paulo/SP, Brasil.

${ }^{2}$ Grupo Banco de Olhos Sorocaba - Sorocaba/SP, Brasil.
}

\author{
Correspondência: \\ Layse Beneli Prado \\ Rua França Pinto no 1253/ 111-A, CEP 04016-035, São Paulo/SP \\ Fone/Fax: 5511 5571-8601 \\ E-mail: laybeneli@gmail.com
}

Recebido em: 10/06/2013

Aceito em: 28/06/2013

\section{INTRODUÇÃO}

O transplante de órgãos e tecidos deixou de ser um tratamento experimental e passou a ser uma alternativa terapêutica extremamente eficaz no tratamento das insuficiências terminais de alguns órgãos e falência de alguns tecidos, culminando em melhoria na qualidade e expectativa de vida. ${ }^{1}$

No ano de 2012, foram realizados no Brasil 15.281 transplantes de córneas, 23.211 transplantes de ossos e 30 de pele, que somados representam cem por cento dos transplantes de tecidos realizados e significativos 80,1, 121,7 e 0,2 transplantes de córneas, ossos e pele por milhão de população, respectivamente, refletindo o aumento desse tipo de transplante nos últimos 10 anos, com destaque para os estados do Paraná e Distrito Federal, quando considerada a doação de tecidos por milhão de população. ${ }^{2}$ 
Layse Beneli Prado, Clayton Gonçalves de Almeida, Kátia Lacerda de Souza, Amanda Silva de Macedo Bezerra, Geórgia Pereira Silveira Souza, Jaquelini Pereira dos Santos, Juliana Massonato Silva, César Augusto Guimarães Marcelino, Antônio Flávio Sanchez Almeida, Andrea Cotait Ayoub

Os tecidos humanos atualmente utilizados para transplante são: córneas, pele, ossos, cartilagem, tendão, menisco, fáscia, valva, vasos e membrana amniótica. O uso clínico dos tecidos diferencia-se do transplante de órgãos pela possibilidade de estocagem em bancos. ${ }^{1}$

Assim como os órgãos, os tecidos são disponibilizados para transplante ou outra finalidade terapêutica somente mediante o consentimento familiar, conforme disposto na Lei $\mathrm{n}$. 10211/2001, mediante a assinatura de um Termo de Doação de Órgãos e Tecidos de Doador Falecido, que respeita o disposto na Lei dos Transplantes n. 9434/97. O termo contempla a possibilidade de doação de até oito tecidos, e a família opta por quais deles serão doados, sendo considerado doador efetivo de tecidos, o doador potencial em morte encefálica ou coração parado do qual a família autorizou a doação de pelo menos um tecido. ${ }^{3-5}$

Um dos entraves à doação de tecidos ainda está relacionado ao desconhecimento sobre as possibilidades de doação de órgãos e tecidos pela população, aspectos religiosos e crenças, culto ao corpo e receio de deformidades, frequentemente observados pelos profissionais envolvidos no processo de doação. ${ }^{6-8}$

A decisão para a doação de tecidos ainda envolve divergências entre famílias e diversos são os motivos de recusa, porém, as produções científicas ainda são deficitárias ao abordar esse aspecto na temática de doação de tecidos, e maior ênfase é concedida à doação de córneas.

Assim, frente à atuação em um Serviço de Procura de Órgãos e Tecidos, que prima pela qualidade e eficácia de seus processos, e à observação na prática cotidiana da existência de números ainda elevados de recusa familiar para a doação de tecidos, identificou-se a necessidade de analisar o desfecho das notificações de potenciais doadores quanto à doação de tecidos e caracterizar os doadores efetivos de tecidos viabilizados por este serviço como um primeiro passo para subsidiar a elaboração e implementação de estratégias que possam minimizar ou reverter essa situação, assim como subsidiar trabalhos futuros.

\section{OBJETIVO}

Este trabalho teve como objetivo analisar o desfecho das notificações de potenciais doadores recebidas por um Serviço de Procura de Órgãos e Tecidos, nos anos de 2011 e 2012, com relação à doação de tecidos e caracterizar os doadores efetivos de tecidos viabilizados nesse período.

\section{MÉTODOS}

O estudo é do tipo documental, retrospectivo, descritivoexploratório, de corte transversal e abordagem quantitativa, realizado em um Serviço de Procura de Órgãos e Tecidos (SPOT) na cidade de São Paulo - Instituto Dante Pazzanese de Cardiologia.
A seleção da amostra foi realizada de forma não aleatória, baseada na análise das notificações de potenciais doadores recebidas pelo SPOT nos anos de 2011 e 2012, totalizando 785 notificações e de prontuários de doadores viabilizados pelo SPOT no mesmo período, que obtiveram consentimento familiar para a doação de tecidos, totalizando 225 prontuários.

Para obter os dados referentes à caracterização dos doadores, foram consideradas as variáveis gênero, idade, causa do óbito, religião e tecidos que obtiveram consentimento familiar para a doação.

Como critérios de inclusão, estão todas as notificações recebidas e prontuários de doadores que obtiveram consentimento familiar para a doação de ao menos um tecido no período selecionado, incluindo aqueles que, apesar do consentimento, a extração não se consolidou devido a causas como ocorrência de sorologias positivas e descarte por parte das equipes transplantadoras. Nos critérios de exclusão estão os prontuários de doadores de coração parado e aqueles que não se enquadraram no período proposto.

Os dados obtidos foram inicialmente registrados em um banco de dados e posteriormente submetidos à análise estatística por meio do programa "A Language and Environment for Statistical Computing”.

Foi utilizado para a análise o Teste Exato de Fisher, selecionado por se tratar de um teste mais exato para amostras menores e pelo fato de o presente trabalho tratar de eventos independentes, considerando nível descritivo de $5 \%$, ou seja p-valor 0,05. Foi considerando ainda Intervalo de Confiança (IC) de $95 \%$.

O projeto foi submetido à análise, apreciação e aprovação do Comitê de Ética em Pesquisa do Instituto Dante Pazzanese de Cardiologia.

\section{RESULTADOS}

Foram analisadas 785 notificações de possíveis doadores recebidas pelo SPOT no período proposto, das quais 471 culminaram na conclusão do protocolo de morte encefálica e realização de entrevista familiar para doação de órgãos e tecidos. Dessas entrevistas, 256 resultaram em consentimento familiar para doação, uma taxa de doação de 54,3\%.

No que diz respeito à doação de tecidos, $31(12,1 \%)$ entrevistas resultaram na recusa total para doação de tecidos e 225 (87,9\%) resultaram em consentimento para a doação de ao menos um tipo de tecido, ou seja, foram doadores efetivos de tecidos.

À caracterização, observou-se que 131 deles $(58,2 \%)$ correspondiam ao sexo masculino e $94(41,8 \%)$ ao sexo feminino, com média de idade de 44,7 anos, sendo a idade mínima de seis e máxima de 85 anos. Na classificação por faixas etárias, houve predominância dos doadores com idades entre 35 e 49 anos, representados por 71 doadores (31,5\%), seguida pelas faixas dos 50 a 64 anos (31,1\%), 18 a 34 anos (19,5\%), 65 a 79 anos (10,2\%), 11 a 17 anos (5,3\%), 6 a 10 anos (1,3\%) e maiores de 80 anos (0,8\%). 
Quanto à religião, 89 (39,6\%) eram católicos, 44 (19,6\%) como evangélicos, 7 (3,1\%) espíritas, 11 (4,9\%) pertencentes a outras religiões como candomblé, budismo, testemunha de Jeová, cristão, $11(4,9 \%)$ não seguiam nenhuma religião e 63 (28\%) não foram especificados.

Em relação à taxa de doação entre as religiões, 100\% das famílias espíritas autorizaram a doação de tecidos, assim como 93,6\% das protestantes, $91,7 \%$ das seguidoras de outras religiões, $84,6 \%$ das que não seguiam nenhuma religião e $84 \%$ das católicas. A Tabela 1 apresenta a taxa de doação de cada um dos tecidos segundo a religião.

Tabela 1 - Taxa de doação de cada tecido segundo a religião. São Paulo, 2013

\begin{tabular}{lcccccc|}
\hline \multicolumn{1}{c}{ Tecidos } & Católicos & Evangélicos & Espíritas & $\begin{array}{c}\text { Outras } \\
\text { religiões }\end{array}$ & $\begin{array}{c}\text { Não } \\
\text { seguem }\end{array}$ & $\begin{array}{c}\text { Não es- } \\
\text { pecificado }\end{array}$ \\
\hline Córneas & $76,4 \%$ & $79,5 \%$ & $100,0 \%$ & $90,9 \%$ & $90,9 \%$ & $93,7 \%$ \\
Pele & $36,0 \%$ & $34,1 \%$ & $85,7 \%$ & $45,5 \%$ & $18,2 \%$ & $60,3 \%$ \\
$\begin{array}{l}\text { Ósteo- } \\
\text { tendinoso }\end{array}$ & $38,2 \%$ & $36,4 \%$ & $85,7 \%$ & $45,5 \%$ & $27,3 \%$ & $60,3 \%$ \\
$\begin{array}{l}\text { Vasos } \\
\text { Valvas }\end{array}$ & $49,4 \%$ & $40,9 \%$ & $85,7 \%$ & $63,6 \%$ & $27,3 \%$ & $74,6 \%$ \\
Cardíacas & $97,8 \%$ & $93,2 \%$ & $100,0 \%$ & $100,0 \%$ & $90,9 \%$ & $95,2 \%$ \\
$\begin{array}{l}\text { Ao menos } \\
\text { um tecido }\end{array}$ & $84,0 \%$ & $93,6 \%$ & $100,0 \%$ & $91,7 \%$ & $84,6 \%$ & $88,7 \%$ \\
\hline
\end{tabular}

Fonte: própria da pesquisa

Dentre as causas-óbito, 90 (40\%) foram de origem traumática, incluindo as causas como traumatismos crânio-encefálicos, ferimentos por arma de fogo e intoxicações exógenas, e 135 (60\%) foram de origem espontânea, incluindo os acidentes vasculares encefálicos hemorrágicos e isquêmicos, tumores cerebrais e encefalopatias.

Considerando o número total de doadores efetivos de tecidos e os tecidos a serem doados, observaram-se 189 (84\%) consentimentos para doação de córneas, 98 (43,6\%) para doação de pele, $102(45,3 \%)$ para doação de ósteo-tendinoso, $125(55,6 \%)$ para doação de vasos e 215 (96\%) para doação de valvas cardíacas (Figura 1).

A média de idade dos doadores de córnea foi de 44,8 anos, de pele 47,8 anos, ósteo-tendinoso 47 anos, vasos 46,6 anos e valvas cardíacas 44,6 anos e para todos os tecidos foi observada a predominância de doação por parte das famílias de indivíduos do sexo masculino, cuja causa-óbito foi de origem espontânea (Figura 1).

Para Intervalo de Confiança de 95\%, e seus limites inferiores e superiores, é esperado que o percentual de doação de córneas esteja entre 78,5 e $88,5 \%$, de pele entre 36,9 e $50,3 \%$, de ósteotendinoso entre 38,7 e $52 \%$, vasos entre 48,8 e $62,1 \%$ e valvas cardíacas entre 91,9 e 97,8\%, apresentados na Tabela 2 .

Os percentuais ficaram dentre o esperado.
Figura 1 - Distribuição dos tecidos efetivamente doados segundo causaóbito e gênero do doador. São Paulo, 2013

\begin{tabular}{|c|c|c|c|c|c|}
\hline \multicolumn{6}{|l|}{$100,00 \%$} \\
\hline \multicolumn{6}{|l|}{$90,00 \%$} \\
\hline \multicolumn{6}{|l|}{$80,00 \%$} \\
\hline \multicolumn{6}{|l|}{$70,00 \%$} \\
\hline \multicolumn{6}{|l|}{$60,00 \%$} \\
\hline \multicolumn{6}{|l|}{$50,00 \%$} \\
\hline \multicolumn{6}{|l|}{$40,00 \%$} \\
\hline \multicolumn{6}{|l|}{$30,00 \%$} \\
\hline \multicolumn{6}{|l|}{$20,00 \%$} \\
\hline \multicolumn{6}{|l|}{$10,00 \%$} \\
\hline \multirow[t]{2}{*}{$0,00 \%$} & & & Ósteo- & & \\
\hline & Córneas & Pele & $\begin{array}{l}\text { Usteo- } \\
\text { tendinoso }\end{array}$ & Vasos & Valvas \\
\hline$\square_{\text {Total }}$ & $84,0 \%$ & $43,6 \%$ & $45,3 \%$ & $55,6 \%$ & $96,0 \%$ \\
\hline $\begin{array}{l}\square \text { Causa } \\
\text { Espontânea }\end{array}$ & $59,3 \%$ & $60,2 \%$ & $59,8 \%$ & $60,0 \%$ & $59,5 \%$ \\
\hline $\begin{array}{l}\square \text { Causa } \\
\text { Traumática }\end{array}$ & $40,7 \%$ & $39,8 \%$ & $40,2 \%$ & $40,0 \%$ & $40,5 \%$ \\
\hline $\begin{array}{l}\square \text { Gênero } \\
\text { Feminino }\end{array}$ & $40,2 \%$ & $43,9 \%$ & $43,1 \%$ & $44,0 \%$ & $41,9 \%$ \\
\hline $\begin{array}{l}\square \text { Gênero } \\
\text { Masculino }\end{array}$ & $59,8 \%$ & $56,1 \%$ & $56,9 \%$ & $56,0 \%$ & $58,1 \%$ \\
\hline
\end{tabular}

Tabela 2 - Relação de significância entre as variáveis de caracterização e os tecidos doados e limites esperados para a doação de tecidos. São Paulo, 2013

\begin{tabular}{|c|c|c|c|c|c|c|}
\hline \multirow[b]{2}{*}{ Tecidos } & \multicolumn{4}{|c|}{ p- valor ${ }^{1}$} & \multicolumn{2}{|c|}{ IC $(95 \%)^{2}$} \\
\hline & Gênero & Idade & $\begin{array}{l}\text { Causa } \\
\text { Óbito }\end{array}$ & Religião & $\mathrm{LI}^{3}$ & $\mathrm{LS}^{4}$ \\
\hline Córneas & 0,357 & 0,957 & 0,711 & 0,051 & $78,54 \%$ & $88,54 \%$ \\
\hline $\begin{array}{l}\text { Ósteo- } \\
\text { tendinoso }\end{array}$ & 0,786 & 0,104 & 1 & 0,1 & $38,71 \%$ & $52,09 \%$ \\
\hline Pele & 0,588 & 0,029 & 1 & 0,001 & $36,98 \%$ & $50,31 \%$ \\
\hline Vasos & 0,497 & 0,099 & 1 & 0 & $48,80 \%$ & $62,16 \%$ \\
\hline $\begin{array}{l}\text { Valvas } \\
\text { cardíacas }\end{array}$ & 0,739 & 0,668 & 0,743 & 0,532 & $91,98 \%$ & $97,85 \%$ \\
\hline $\begin{array}{l}\text { Ser doador } \\
\text { de tecidos }\end{array}$ & 0,181 & $>0,050$ & 0,44 & 0,587 & $83,25 \%$ & $91,62 \%$ \\
\hline
\end{tabular}

Fonte: própria da pesquisa

${ }^{1}$ p-valor calculado através do teste exato de Fisher; ${ }^{2}$ Intervalo de Confiança

${ }^{3}$ Limite Inferior e ${ }^{4}$ Limite Superior do consentimento para a doação dos diferentes tecidos.

\section{DISCUSSÃO}

Como é conhecido, a possibilidade de captação de órgãos e tecidos está diretamente relacionada ao número de óbitos ocorridos em pacientes internados em Unidades de Tratamento Intensivo e unidades que disponham de equipamento de ventilação mecânica, ou óbitos ocorridos em uma instituição de um modo geral, sendo considerada adequada a obtenção mínima de $60 \%$ de consentimento familiar à doação, entre os casos em que foi realizada a entrevista familiar. ${ }^{9}$ 
A taxa de doação encontrada ainda se mostra aquém do esperado (54,3\%), porém não distante de ser atingido, sofrendo ainda influência por parte de fatores culturais, religiosos, mitos que permeiam o assunto, baixa instrução da população sobre o processo de doação de órgãos e tecidos, dentre outros, passíveis ou não de intervenções. ${ }^{6} \mathrm{~A}$ taxa de doação no âmbito nacional no ano de 2012 foi de $59 \%{ }^{2}$

A análise das variáveis de caracterização desses doadores corrobora com os resultados descritos pelo Registro Brasileiro de Transplantes, no ano de 2012, para os doadores de órgãos e tecidos em situação de morte encefálica, que demonstra predominância de doadores do sexo masculino (60\%), de causas-óbito não traumáticas (60\%) e da faixa etária dos 35 aos 49 anos $(28 \%){ }^{2}$ Dados compatíveis também são encontrados em inúmeros outros estudos desenvolvidos, como os de Freire et al, Noronha et al e Moraes et al que somente divergiram deste estudo por demonstrar predominância do sexo feminino, e Fusco et al, que somente divergiu por encontrar predomínio de causas-óbito traumáticas. ${ }^{10-13}$

No tocante à religião, embora observada prevalência da religião católica dentre os doadores de tecidos, cabe ressaltar que, dentre todas as famílias que autorizaram a doação de algum órgão ou tecido, $100 \%$ das famílias espíritas autorizaram a doação de tecidos, assim como $93,6 \%$ das protestantes e $91,7 \%$ das seguidoras de outras religiões, contra $84 \%$ das católicas, demonstrando menor taxa de doação por parte desta.

A prevalência da religião católica entre os doadores pode ser amparada pelas estatísticas brasileiras, as quais mostram que $64,6 \%$ das pessoas declaram ser católicas, ou seja, a proporção de católicos ainda é majoritária. ${ }^{14}$

Ferrazzo et al, em estudo recente que analisou a interferência da religião na decisão do doador e/ou da família em consentir a doação de órgãos e tecidos, concluiu, após revisão integrativa da literatura, que nenhuma religião posiciona-se de modo absoluto contrária à doação, e que pode ser considerada como aconselhadora no processo de tomada de decisão, tornando mais fácil a decisão pelo consentimento quando há apoio por parte da crença religiosa. Ressalta ainda que a crença da morte relacionada à parada do coração e os rituais ligados ao corpo após o falecimento exercem importante influência na adesão ou não à doação. ${ }^{15}$

Contudo, apesar do perfil traçado, não foi possível estabelecer uma relação de significância entre as variáveis de caracterização (gênero, idade, causa-óbito, religião) e os tecidos que foram doados, o que é demonstrado pelos valores de $\mathrm{p}$ superiores ao $\mathrm{p}$-valor de 0,05 estabelecido neste trabalho, exceto no que diz respeito à relação entre a doação dos tecidos pele e vasos e a variável religião, conforme também mostrado anteriormente na Tabela 2.

Os valores de $\mathrm{p}$ obtidos da relação tecido pele $\mathrm{x}$ religião $(\mathrm{p}=$ $0,001)$ e da relação tecido vasos x religião $(\mathrm{p}=0)$ demonstraram relação significativa, onde se pode inferir que famílias espíritas doam mais os tecidos pele e vasos se comparadas às demais religiões.
No que diz respeito aos tecidos que foram doados, as córneas, após as valvas cardíacas, destacam-se pela doação em $84 \%$ dos consentimentos familiares. A prevalência da doação de córneas dentre os tecidos foi unânime nos resultados apresentados por diferentes estudos, assim como o tecido ósteo-tendinoso, pele e vasos são considerados os tecidos menos doados. ${ }^{10,11,13,16}$ Estudo recente realizado no Nordeste apresentou o percentual de doação de córneas de $81,5 \%{ }^{16}$

A aceitação para a doação de tecidos em geral foi representada por $87,9 \%$ de autorizações para a doação de, ao menos, um tecido. Contudo, cabe pontuar que em 13,3\% dos casos, esse tecido foi somente valva cardíaca, e pelas situações vivenciadas na atuação profissional em um SPOT, não raras as vezes, foi verbalizado pelo familiar responsável pelo consentimento que a doação dessas estaria relacionada à doação do coração e portanto não haveria porque não doá-las, diferente dos demais tecidos, cuja extração seria mais aparente e geraria receio de deformidades no corpo. Isto nos leva a inferir tratar-se esse um dos motivos de serem as valvas cardíacas o tecido mais doado e a refletir sobre estratégias a driblar o "pré-conceito" relacionado à doação dos demais tecidos.

Recusa familiar é o principal entrave à não efetivação da doação e, no que diz respeito aos tecidos, pode ser atribuída ao conhecimento restrito da população quanto à possibilidade da doação, sem que haja desfiguração do corpo do doador ou receio quanto a reconstituição desse. ${ }^{11,13}$

Vários outros aspectos influenciam nessa decisão para a doação, sendo os mais comumente observados e também trazidos pela literatura, o respeito à vontade do potencial doador, valores, crenças e aspectos religiosos em geral, como manutenção da integridade corporal para a vida após a morte, a não confiança no diagnóstico de $\mathrm{ME}$ e abordagem inadequada sobre a possibilidade de doação de órgãos e tecidos. ${ }^{8,11}$

Esse paradigma aponta para a necessidade de intervenções junto à população, no intuito de esclarecê-la sobre o processo de doação de órgãos e tecidos e conscientizá-la da sua importância, estimulando o consentimento familiar, além de enfatizar a importância de cada indivíduo que deseja que seus órgãos sejam doados comunicar a sua família sobre isso, já que é sabido que quando a família conhece o desejo do potencial doador em vida, as chances de consentimento são maiores em comparação àquelas que desconhecem tal desejo. ${ }^{10}$

A realização de campanhas de educação à população, planejamento e implementação de programas educativos contínuos que forneçam informações sobre o processo de doação voltado para a conscientização e o esclarecimento da população, bem como para o incentivo à doação de órgãos e tecidos, e capacitação dos profissionais de saúde envolvidos no processo, por meio de programas de educação permanente com o objetivo de incentivar o ato de doação, e torná-los aptos para uma entrevista familiar de qualidade, informativa e humanizada, são estratégias que tornam tais objetivos passíveis de serem atingidos. ${ }^{8,10,16}$ 
Estudos que se voltam especificamente à doação de tecidos, perfil de seus doadores, aspectos socioeconômicos, culturais, religiosos e demográficos relacionados ainda são encontrados em números reduzidos, embora sejam de grande importância para fornecer subsídios ao aprimoramento dessas estratégias, possibilitando maior conhecimento das populações que necessitam de intervenções.

\section{CONCLUSÃO}

O presente estudo possibilitou conhecer o desfecho das notificações recebidas de potenciais doadores recebidas e caracterizar os doadores efetivos de tecidos viabilizados pelo serviço em questão no período proposto.

Foi observado que dentre as 785 notificações de possíveis doadores recebidas, $60 \%$ culminaram na realização de entrevista familiar, com taxa de doação de 54,3\%. Dos consentimentos, $87,9 \%$ resultaram em consentimento para a doação de ao menos um tipo de tecido.

$\mathrm{Na}$ caracterização dos doadores de tecidos, foi encontrada predominância de indivíduos do sexo masculino, referidos como católicos, com média de idade de 44,7 anos e faixa etária prevalente entre 35 e 49 anos, cuja causa óbito predominante foi de origem espontânea, incluindo os acidentes vasculares encefálicos isquêmicos e hemorrágicos, tumores e encefalopatias.

Os tecidos mais doados foram as valvas cardíacas, com $96 \%$ de consentimentos para a doação, seguido pelas córneas com $84 \%$, vasos com $55,6 \%$, ósteo-tendinoso com $45,3 \%$ e pele, 43,6\%. Contudo, apesar do perfil traçado, não foi possível estabelecer uma relação estatística de significância entre as variáveis de caracterização (gênero, idade, causa óbito, religião) e todos os tecidos que foram doados, e sim somente aos tecidos pele e vasos e a variável religião.

Números aquém do esperado para a doação de tecidos e as ainda elevadas taxas de recusa familiar para doação levam à necessidade de estratégias educativas voltadas à população para sua instrução, desmistificação de aspectos relacionados ao processo, conscientização da importância desse ato e da necessidade de informar aos parentes próximos quanto ao desejo de ser doador, além da capacitação dos profissionais de saúde visando a incorporação de ações relacionadas à doação em suas rotinas, e formação de indivíduos qualificados ao tratar desse assunto junto às famílias, a fim de elevar a disponibilidade de tecidos para transplante e assim contribuir para o aumento da sobrevida daqueles que aguardam pelo procedimento nas filas de espera.

Para isso, conhecer mais a fundo os motivos específicos da não autorização da doação de tecidos, alegados pelos familiares no ato da entrevista, mostra-se de grande valia para o planejamento dessas estratégias. Alguns desses motivos, citados brevemente em nossa discussão, como por exemplo, o conhecimento restrito da população quanto à possibilidade da doação de tecidos, sem que haja desfiguração do corpo do doador ou receio quanto à reconstituição do mesmo pós-extração, são passíveis de serem modificados por meio da atuação do entrevistador, que pode se antecipar no momento da entrevista, esclarecendo possíveis dúvidas que poderiam ser levantadas pelos familiares, minimizando assim a ansiedade dos mesmos, adiantando-se também no esclarecimento de mitos que possam levar a formação de pré-conceito equivocado sobre a doação de tecidos e, consequentemente, à recusa familiar, assim como inúmeros outros motivos que devem ser analisados pontualmente e trabalhados para evitar possível negativa.

\section{ABSTRACT}

The amount of tissue transplants has increased significantly in the past ten years. The potential donor diagnosed with brain death or cardiac arrest whose family authorized the donation of at least one tissue is considered an effective tissue donor. Purpose: To analyze the outcome of reports on potential donors achieved by the Organ and Tissue Procurement Service in 2011 and 2012 related to the tissue donation and characterizing the effective tissue donors approved during that period. Method: Documental retrospective, descriptive-exploratory research of quantitative approach conducted in an Organ and Tissue Procurement Service in São Paulo through the analysis of reports received along 2011 and 2012 and from medical records of effective tissue donors. Results: From 785 reports of potential donors, 471 (60\%) led to interview with the family, and from those reports, $256(54.3 \%)$ attained family consent for the donation, whereby $225(87.9 \%)$ consented to donate at least one tissue. There was predominance of male donors (58.2\%) identified as Catholics (39.6\%), with mean age of 44.7 years and non-traumatic origin death causes (60\%). Tissues most often donated were heart valves (96\%), followed by corneas (84\%), vessels (55.6\%), bone-tendon tissues (45.3\%) and skin (43.6\%). Conclusion: It was not possible to set a significant relationship between variables of characterization and all tissues donated. Numbers below expectations regarding the tissue donation require educational strategies aimed at the population, and professional training aimed to increase the availability of tissue for transplantation, thus contributing to the increased survival of thousands of people.

Keywords: Tissue Donors; Brain Death; Tissue Transplantation; Tissue and Organ Procurement; Nursing. 
Layse Beneli Prado, Clayton Gonçalves de Almeida, Kátia Lacerda de Souza, Amanda Silva de Macedo Bezerra, Geórgia Pereira Silveira Souza, Jaquelini Pereira dos Santos, Juliana Massonato Silva, César Augusto Guimarães Marcelino, Antônio Flávio Sanchez Almeida, Andrea Cotait Ayoub

\section{REFERÊNCIAS}

1- Associação Brasileira de Transplante de Órgãos. Diretrizes Básicas para Captação e Retirada de Múltiplos Órgãos e Tecidos. São Paulo: ABTO, Jan/Dez, 2009.

2- Associação Brasileira de Transplante de Órgãos. Registro Brasileiro de Transplantes-RBT. Dados Numéricos da doação de órgãos e transplantes realizados por estado e instituição no período de Janeiro a Dezembro de 2012. 2012; 18(4).

3- Brasil. Lei n. 10.211, de 23 de março de 2001. Altera dispositivos da Lei $\mathrm{n}^{\circ}$ 9.434, de 4 de fevereiro de 1997, que "dispõe sobre a remoção de órgãos, tecidos e partes do corpo humano para fins de transplante e tratamento". Diário Oficial da República Federativa do Brasil, Brasília, 24 Mar. 2001. Edição extra. p.06-E.

4- Brasil. Lei n. 9.434, de 4 de fevereiro de 1997. Dispõe sobre a remoção de órgãos, tecidos e partes do corpo humano para fins de transplante e tratamento dá outras providências. Diário Oficial da República Federativa do Brasil, Brasília, 05 Fev. 1997. Seção 1. p. 2.191.

5- Brasil. Resolução SS-151, de 13 de agosto de 2010. Dispõe sobre a estrutura organizacional e operacional do Sistema Estadual de Transplantes de São Paulo. Diário Oficial do Estado de São Paulo, no 154, 14 Ago. 2010. Seção 1. p. 29 (Saúde).

6- Roza BA, Garcia VD, Barbosa SFF, Mendes KDS, Schirmer J. Doação de órgãos e tecidos: relação com o corpo em nossa sociedade. Acta Paul Enferm. 2010;23(3):417-22.

7- Quintana AM, Arpini DM. Doação de órgãos: possíveis elementos de resistência e aceitação.Bol. psicol. 2009;59(130):91-102.

8- Moraes EL, Massarollo MCKB. Recusa de doação de órgãos e tecidos para transplante relatados por familiares de potenciais doadores. Acta Paul Enferm. 2009;22(2):131-5.
9- Brasil. Portaria n. 1.262, de 16 de Junho de 2006. Aprova o Regulamento Técnico para estabelecer as atribuições, deveres e indicadores de eficiência e do potencial de doação de órgãos e tecidos relativos às Comissões Intra-hospitalares de Doação de Órgãos e Tecidos para Transplante. Diário Oficial do Estado de São Paulo.2006.

10- Freire ILS, Vasconcelos QLDAQ, Oliveira e Araújo R, Pinto JTJM, Torres GV. Caracterização dos potenciais doadores de órgãos e tecidos para transplantes. Rev enferm UFPE on line. 2013;Jan;7(1):184-91.

11- Noronha MGO, Seter GB, Perini LD, Salles FMO, Nogara MAS. Estudo do perfil dos doadores elegíveis de órgãos e tecidos e motivos da não doação no Hospital Santa Isabel em Blumenau, SC. Rev Assoc Med Rio Grande Do Sul. 2012;julset;56(3):199-203.

12- Moraes EL, Silva LBB, Moraes TC, Paixão NCS, Izumi NMS, Guarino AJ. O perfil de potenciais doadores de órgãos e tecidos. Rev. Latino-Am. Enfermagem. 2009;Set-Out;17(5):716-20.

13- Fusco CC, Marcelino CAG, Araújo MN, Ayoub AC, Martins CP. Perfil dos doadores efetivos de múltiplos órgãos e tecidos viabilizados pela organização de procura de órgãos de uma instituição pública de cardiologia. JBT J Bras Transpl. 2009;12:1109-12.

14- Brasil. Ministério do Planejamento, Orçamento e Gestão. Censo Gemográfico de 2010. Características gerais da população, religião e pessoas com deficiência. Rio de Janeiro: Instituto Brasileiro de Geografia e Estatística (IBGE). 2010. p.1-215.

15- Ferrazzo S, Vargas MAO, Mancia JR, Ramos FRS. Crença religiosa e doação de órgãos e tecidos: revisão integrativa da literatura. R. Enferm. UFSM. 2011;Set/Dez;1(3):449-60.

16- Aguiar MIF, Araújo TOM, Cavalcante MMS, Chaves ES, Rolim ILTP. Perfil de doadores efetivos de órgãos e tecidos no Estado do Ceará . Rev. Min. Enferm. 2010;Jul-Set;14(3):353-60. 